\title{
Renal dysfunction and prognosis of COVID- 19 patients: a hospital-based retrospective cohort study
}

Hui-Xian Xiang ${ }^{1 \dagger}$, Jun Fei ${ }^{1 \dagger}$, Ying Xiang ${ }^{1 \dagger}$, Zheng $\mathrm{Xu}^{1}$, Ling Zheng ${ }^{1}$, Xiu-Yong $\mathrm{Li}^{2}$, Lin Fu ${ }^{1,3^{*}}$ and Hui Zhao ${ }^{{ }^{*}}$

\begin{abstract}
Introduction: Increasing evidence indicate that coronavirus disease 2019 (COVID-19) is companied by renal dysfunction. However, the association of Severe Acute Respiratory Syndrome Coronavirus-2 (SARS-CoV-2)-induced renal dysfunction with prognosis remains obscure.

Materials and methods: All 154 patients with COVID-19 were recruited from the Second People's Hospital of Fuyang City in Anhui, China. Demographic characteristics and laboratory data were extracted. Renal dysfunction was evaluated and its prognosis was followed up based on a retrospective cohort study.

Results: There were 125 (81.2\%) mild and 29 (18.8\%) severe cases in 154 COVID-19 patients. On admission, 16 (10.4\%) subjects were accompanied with renal dysfunction. Serum creatinine and cystatin C were increased and estimated glomerular filtration rate (eGFR) was decreased in severe patients compared with those in mild patients. Renal dysfunction was more prevalent in severe patients. Using multivariate logistic regression, we found that male gender, older age and hypertension were three importantly independent risk factors for renal dysfunction in COVID-19 patients. Follow-up study found that at least one renal function marker of 3.33\% patients remained abnormal in 2 weeks after discharge.
\end{abstract}

Conclusion: Male elderly COVID-19 patients with hypertension elevates the risk of renal dysfunction. SARS-CoV-2induced renal dysfunction are not fully recovered in 2 weeks after discharge.

Keywords: Severe acute respiratory syndrome coronavirus-2, Coronavirus disease 2019, Renal dysfunction, Prognosis

\section{Background}

At the winter of 2019, Coronavirus Disease 2019 (COVID-19), an emerging infectious disease with unclear etiology broke out in Wuhan City, Hubei Province, China [1]. Later, this unknown virus was clarified and named as severe acute respiratory syndrome coronaviruse-2 (SARS-CoV-2) [2, 3]. Now, it has been pandemic across the world. Up to January 1st, 2021,

\footnotetext{
*Correspondence: fulindev@126.com; zhaohuichenxi@126.com

${ }^{+}$Hui-Xian Xiang, Jun Fei and Ying Xiang contributed equally to this work. 'Second Affiliated Hospital, Anhui Medical University, Furong Road no 678, Hefei 230601, Anhui Province, China

Full list of author information is available at the end of the article
}

there were approximate 90 million accumulated confirmed patients of SARS-CoV-2 infections in 220 countries, of them about one million cases have died [4]. All humanity is sustained huge disaster from SARS-CoV-2 $[5,6]$. Therefore, all medical staff, scientific research personnel and all sectors of the entire society must cooperate to decrease COVID-19 spread and seek for effective cures drugs and method.

Previous studies have demonstrated that COVID-19 patients mainly accompanied with fever, diarrhea, dry cough, lymphocyte reduction and radiographic evidence of pneumonia [7]. Now, more and more studies have

C C The Author(s). 2021 Open Access This article is licensed under a Creative Commons Attribution 4.0 International License, which permits use, sharing, adaptation, distribution and reproduction in any medium or format, as long as you give appropriate credit to the original author(s) and the source, provide a link to the Creative Commons licence, and indicate if changes were made. The images or other third party material in this article are included in the article's Creative Commons licence, unless indicated otherwise in a credit line to the material. If material is not included in the article's Creative Commons licence and your intended use is not permitted by statutory regulation or exceeds the permitted use, you will need to obtain permission directly from the copyright holder. To view a copy of this licence, visit http://creativecommons.org/licenses/by/4.0/ The Creative Commons Public Domain Dedication waiver (http://creativecommons.org/publicdomain/zero/1.0/) applies to the data made available in this article, unless otherwise stated in a credit line to the data. 
confirmed that SARS-CoV-2 not only evoked severe acute respiratory syndrome, but also induced multiple organ injuries, such as myocardial injury, lymphocyte reduction and even liver dysfunction [8-11]. Nevertheless, the clinical characteristics of renal dysfunction caused by SARS-CoV-2 are rarely described. Moreover, the clinical significance of SARS-CoV-2-induced renal dysfunction and its recovery situation are still ambiguous.

This research primarily explored whether SARS-CoV2-evoked renal dysfunction, its risk factors and prognosis after discharge among COVID-19 patients. Our data reveal that male, higher age and hypertension are three independently risk factors of renal dysfunction. Our research firstly demonstrates that SARS-CoV-2-evoked renal dysfunction are not fully recovered in 2 weeks after discharge.

\section{Materials and methods Subjects}

In this study, 154 COVID-19 patients were enrolled from the Second People's Hospital of Fuyang City of Anhui Province from January 1 to February 30, 2020. The Second People's Hospital of Fuyang City was the designated infectious hospital in Fuyang City. All patients were diagnosed with SARS-CoV-2 injection using RTPCR on pharyngeal swab specimens. The diagnostic criteria of SARS-CoV-2 injection was referred to the New Coronavirus Pneumonia Prevention and Control Program (8th edition). There was no death in Fuyang City. The severity of patients with COVID-19 were accessed through oxygenation index based on the New Coronavirus Pneumonia Prevention and Control Program [12]. Mild case, defined as oxygenation index higher than 300; For severe case, whose oxygenation index was from 200 to 300; For critically ill case, whose oxygenation index was lower than 200. Finally, the prognosis of patients with COVID-19 was observed in 2 weeks after discharge among 150 subjects. Renal function was assessed in 150 patients with COVID-19. This project was approved by the institutional ethics board of the Second People's Hospital of Fuyang City (No. 2020-5). Individual signed informed consent was gained from patients.

\section{Data collection}

Demographic data and clinical characteristics were collected. The severity of COVID-19 was evaluated. The hospital stay was calculated in COVID-19 patients. Uric acid, urea nitrogen, creatinine, cystatin $\mathrm{C}$ and estimated glomerular filtration rate (eGFR) were measured. All laboratory tests were performed in the clinical laboratory of the Second People's Hospital of Fuyang City.

\section{Statistical analysis}

Statistical analyses were conducted using SPSS software (version 19.0). Categorical variables were expressed with frequencies and percentages. All continuous variables were shown as medians with interquartile ranges (P25, P75). Categorical variables were evaluated using Fisher exact test or $\chi^{2}$ test. Continuous variables were analyzed through ANOVA and Mann-Whitney U test. Moreover, the main risk factors of renal dysfunction were examined using multivariate logistic regression models and potential confounders were adjusted. Obvious differences were reported with $P$ values less than 0.05 .

\section{Results}

\section{Demographic information and clinical manifestations}

All 154 COVID-19 patients were enrolled and analyzed in the Second People's Hospital of Fuyang City of Anhui Province. We found that mild patient, was 125 (81.2\%) (Table 1). Severe patient accounted for 18.8\% (Table 1). Besides, the demographic data were evaluated. As shown in Table 2, of COVID-19 patients, 92 (59.7\%) were male and $62(40.3 \%)$ were female. There were 69 patients $<39$ years old, 68 patients aged between 40 and 59 years, and 17 patients $>60$ years old. Among 154 COVID-19 patients, $22(14.3 \%)$ subjects accompanied with hypertension, 8 (5.19\%) with diabetes and $12(7.79 \%)$ subjects with other chronic diseases.

\section{Correlation of renal dysfunction and the severity in COVID-19 patients}

The correlation between renal dysfunction and the severity of COVID-19 was analyzed. Serum renal function indexes, including uric acid, urea nitrogen, creatinine, cystatin $\mathrm{C}$ and eGFR, were measured. As shown in Table 1 , the level of serum creatinine and cystatin $C$ were higher, the level of serum eGFR was lower in severe patients than those in mild patients. There was no difference of uric acid, urea nitrogen and cystatin $\mathrm{C}$ between mild patients and severe patients. Renal dysfunction was

Table 1 The association between the severity of COVID-19 patients and renal functional indexes

\begin{tabular}{lll}
\hline Parameters & Mild & Severe \\
\hline Cases, N (\%) & $125(81.2)$ & $29(18.8)$ \\
Uric acid $(\mu \mathrm{mol} / \mathrm{L})$ & $239.0(180.0,306.8)$ & $218.0(186.0,247.5)$ \\
Urea nitrogen $(\mathrm{mmol} / \mathrm{L})$ & $3.7(3.1,4.7)$ & $4.0(2.8,5.4)$ \\
Creatinine $(\mu \mathrm{mol} / \mathrm{L})$ & $65.0(52.0,77.0)$ & $70.0(54.5,83.5) *$ \\
Cystatin C $(\mathrm{mg} / \mathrm{L})$ & $0.81(0.70,0.92)$ & $0.89(0.71,0.93) *$ \\
eGFR $(\mathrm{mL} / \mathrm{min})$ & $126.4(103.4,150.6)$ & $118.6(99.3,142.7) *$ \\
Renal dysfunction, N (\%) & $5(4.0)$ & $11(37.9)$ \\
\hline
\end{tabular}

The levels of renal function were expressed with median (P25, P75) Renal dysfunction was defined as any of renal functional indexes beyond normal range

${ }^{*} P<0.05$ 
Table 2 The effects of demographic characteristics and complications on renal function indexes

\begin{tabular}{|c|c|c|c|c|c|c|}
\hline & Cases, N (\%) & Uric acid ( $\mu \mathrm{mol} / \mathrm{L})$ & Urea nitrogen $(\mathrm{mmol} / \mathrm{L})$ & Creatinine $(\mu \mathrm{mol} / \mathrm{L})$ & Cystatin C (mg/L) & eGFR (mL/min) \\
\hline \multicolumn{7}{|l|}{ Gender } \\
\hline Male & $92(59.7)$ & $274.0(218.0,336.0)$ & $4.3(3.6,5.2)$ & $75.0(66.0,82.0)$ & $0.84(0.75,0.94)$ & $110.3(97.0,133.1)$ \\
\hline Female & $62(40.3)$ & $201.0(157.5,245.0) * *$ & $3.2(2.7,3.6) *$ & $51.5(44.0,57.0) * *$ & $0.72(0.64,0.81) *$ & $142.2(124.3,175.3) * *$ \\
\hline \multicolumn{7}{|l|}{ Age } \\
\hline$<39$ & $69(44.8)$ & $253.0(191.5,306.5)$ & $3.6(3.2,4.3)$ & $65.0(49.5,78.5)$ & $0.76(0.66,0.87)$ & $133.5(108.5,181.6)$ \\
\hline $40-59$ & $68(44.2)$ & $243.0(186.0,329.0)$ & $3.6(3.0,4.8)$ & $63.5(53.0,76.3)$ & $0.80(0.71,0.94)$ & $122.9(103.4,142.9) *$ \\
\hline$>60$ & $17(11.0)$ & $288.0(229.5,347.0) * \#$ & $5.3(3.6,6.9) * \#$ & $72.0(60.5,87.0) * *^{*}$ & $0.90(0.81,1.39) * * \#$ & $105.4(84.5,121.1) \#$ \\
\hline \multicolumn{7}{|c|}{ Hypertension } \\
\hline Yes & $22(14.3)$ & $225.0(195.0,354.5)$ & $5.1(3.1,6.7)$ & $65.0(52.0,78.0)$ & $0.89(0.75,1.07)$ & $110.0(94.3,144.1)$ \\
\hline No & $132(85.7)$ & $235.5(178.3,295.5)$ & $3.7(3.1,4.6)^{* *}$ & $66.0(52.0,77.0)$ & $0.80(0.69,0.89) *$ & $126.4(103.2,148.7)$ \\
\hline \multicolumn{7}{|l|}{ Diabetes } \\
\hline Yes & $8(5.2)$ & $327.0(235.0,372.0)$ & $6.3(5.5,10.6)$ & $72.0(57.0,108.0)$ & $0.99(0.87,1.54)$ & $106.2(63.9,133.0)$ \\
\hline No & $146(94.8)$ & $234.0(182.0,298.0) * *$ & $3.7(3.1,4.6)^{* *}$ & $65.0(52.0,77.0) *$ & $0.80(0.70,0.90) * *$ & $126.0(103.3,150.1) *$ \\
\hline \multicolumn{7}{|c|}{ Other diseases } \\
\hline Yes & $12(7.8)$ & $227.0(190.5,344.5)$ & $4.5(2.5,6.0)$ & $69.0(59.5,76.8)$ & $0.90(0.81,0.94)$ & $109.8(96.0,129.8)$ \\
\hline No & $142(92.2)$ & $236.0(181.0,298.0)$ & $3.7(3.1,4.7)$ & $65.0(52.0,77.8)$ & $0.79(0.70,0.91)$ & $126.5(103.3,150.1) *$ \\
\hline
\end{tabular}

The levels of renal function were expressed with median (P25, P75)

Cases in Gender, compared with "Male", ${ }^{*} P<0.05$, ${ }^{* *} P<0.01$

Cases in Age, compared with " $<39$ ", ${ }^{*} P<0.05$, ${ }^{* *} P<0.01$; Compared with "40-59", ${ }^{\#} P<0.05,{ }^{\# \#} P<0.01$

Cases in Hypertension, Diabetes and Other diseases, compared with "Yes", ${ }^{*} P<0.05$, ${ }^{* *} P<0.01$

defined as any of renal functional indexes beyond normal range. Our results indicated that 5 (4.0\%) cases with renal dysfunction were in mild patients and 11 (37.9\%) cases with renal dysfunction were in severe patients on admission. Besides, the correlations between renal function indexes and inflammatory cytokines were analyzed. As shown in Fig. 1, no significant correlations were observed between inflammatory cytokines with uric acid and creatinine. Moreover, there was a weekly positive correlation between urea nitrogen with CRP $(r=0.208$, $P=0.012)$ and IL-6 $(r=0.421, P<0.001)$. Further analysis indicated that cystatin $C$ was negatively correlated with IL-6 $(r=-0.472, P=0.001)$ and eGFR was inversely correlated with CRP $(r=-0.210, P=0.012)$ among COVID-19 patients.

\section{Male elderly cases with hypertension elevated the risk of renal dysfunction}

The influences of demographic characteristics and complications on renal dysfunction were accessed among COVID-19 patients. As shown in Table 2, the level of uric acid, urea nitrogen, creatinine and cystatin $C$ were higher and eGFR were lower in males than those in females. The effect of age on renal function was analyzed. The results revealed that the level of eGFR was lower in patients between 40 to 59 years than those of younger than 39 years. Moreover, our results also revealed that the levels of uric acid, urea nitrogen, creatinine and cystatin $\mathrm{C}$ were higher in patients $>60$ years than those younger patients. The level of eGFR was lowest in the patients $>60$ years. In addition, the effects of comorbidities on renal dysfunction were then accessed. As shown in Table 2, urea nitrogen was increased and cystatin C was reduced in COVID-19 patients with hypertension. In addition, uric acid, urea nitrogen, creatinine and cystatin $C$ were increased and eGFR was decreased in COVID-19 patients with diabetes. Meanwhile, we found that the level of eGFR was slightly lower in COVID-19 patients with other chronic diseases than those without chronic disease. In addition, the risk factors of renal dysfunction were analyzed using multivariate logistic regression among COVID-19 patients. As shown in Table 3, the $O R$ of male gender was 1.465 (95\% Cl: $1.124,4.001)$, the $O R$ of age was $1.945(95 \% \mathrm{Cl}: 1.024,3.128)$ and the OR of hypertension was 2.345 (95\% Cl: 1.135, 3.458) for renal dysfunction, respectively. Diabetes and other diseases had no obvious effect on renal dysfunction in COVID-19 patients (Table 3).

\section{Renal function indexes were abnormal in 2 weeks after discharge}

The recovery condition of renal dysfunction was investigated in COVID-19 patients. Renal function indexes were measured and compared between on admission and in 2 weeks after discharge. As shown in Table 4, there was no significant difference of urea nitrogen, creatinine, cystatin $\mathrm{C}$ and eGFR between on admission and after discharge in COVID-19 patients. However, the 

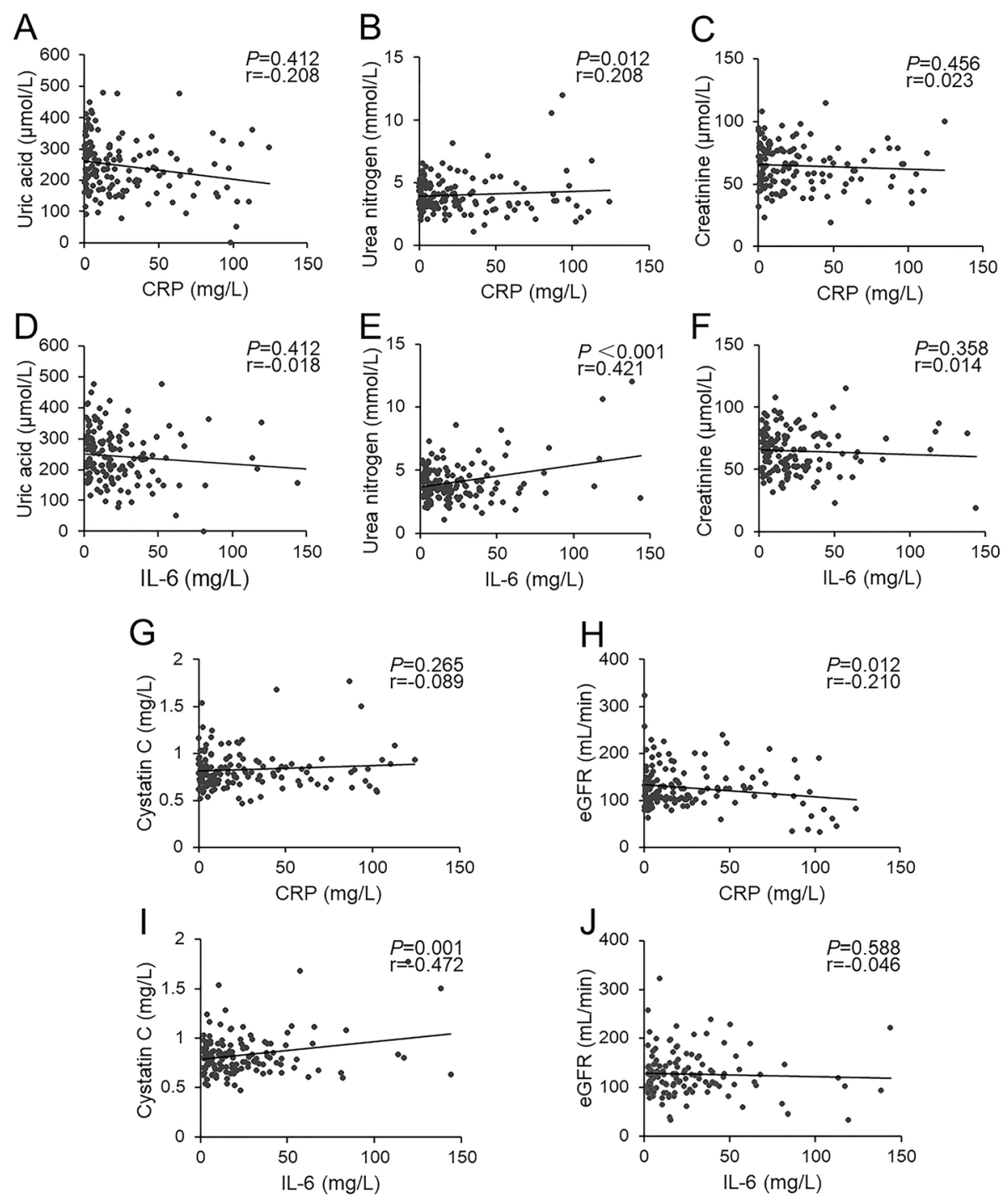

Fig. 1 The correlations between inflammatory cytokines and renal function indexes among COVID-19 patients. a, d Correlations between inflammatory cytokines and uric acid were analyzed among COVID-19 patients. a CRP; (D) IL-6. b, e Correlations between inflammatory cytokines and urea nitrogen were analyzed among COVID-19 patients. b CRP; e IL-6. c, f Correlations between inflammatory cytokines and creatinine were analyzed among all COVID-19 patients. c CRP; $\mathbf{f} \mid \mathrm{L}-6 . \mathbf{g}$, i Correlations between inflammatory cytokines and cystatin C were analyzed among all COVID-19 patients. $\mathbf{g}$ CRP; i IL-6. h, j Correlations between inflammatory cytokines and cystatin C were analyzed among all COVID-19 patients. $\mathbf{h}$ $\mathrm{CRP} ; \mathbf{j} \| \mathrm{L}-6$

Table 3 Multivariable logistic regression analysis between demographics characteristics and complications with renal dysfunction among COVID-19 patients

\begin{tabular}{lllll}
\hline & $\boldsymbol{\beta}$ & Wald & $\boldsymbol{P}$ value & OR $(\mathbf{9 5} \% \mathbf{C l})$ \\
\hline Male & 0.584 & 4.123 & 0.008 & $1.465(1.124,4.001)$ \\
Age & 0.784 & 6.512 & 0.021 & $1.945(1.024,3.128)$ \\
Hypertension & 0.457 & 2.354 & 0.031 & $2.345(1.135,3.458)$ \\
Diabetes & 0.468 & 2.324 & 0.564 & $0.865(0.654,1.231)$ \\
Other diseases & 0.384 & 1.128 & 0.387 & $0.721(0.324,1.178)$ \\
\hline
\end{tabular}

level of uric acid was increased in 2 weeks after discharge than on admission. On admission, 4 (2.6\%) patients with uric acid, $4(2.6 \%)$ patients with urea nitrogen, $1(0.6 \%)$ patient with creatinine and $6(3.9 \%)$ patients with cystatin $\mathrm{C}$ were above the normal range. Besides, 6 (3.9\%) patients with eGFR were below the normal range. There was total 16 (10.4\%) COVID-19 subjects with renal dysfunction on admission. The prognosis of COVID-19 patients with renal dysfunction was tracked until 2 weeks after discharge. After discharge, 1 $(0.7 \%)$ patient with creatinine and $2(1.4 \%)$ patients with cystatin $\mathrm{C}$ were above the normal range. Additionally, 2 
Table 4 Renal functional indexes on admission and after discharge among COVID-19 patients

\begin{tabular}{|c|c|c|c|c|c|c|}
\hline \multirow[t]{2}{*}{ Renal indexes } & \multicolumn{3}{|c|}{ On admission $(N=154)$} & \multicolumn{3}{|c|}{ Discharge $(N=150)$} \\
\hline & $\begin{array}{l}\text { Median (P25, } \\
\text { P75) }\end{array}$ & $\begin{array}{l}\text { Below the range, } \mathrm{N} \\
(\%)\end{array}$ & $\begin{array}{l}\text { Above the range, } \mathrm{N} \\
(\%)\end{array}$ & $\begin{array}{l}\text { Median (P25, } \\
\text { P75) }\end{array}$ & $\begin{array}{l}\text { Below the range, } \mathrm{N} \\
(\%)\end{array}$ & $\begin{array}{l}\text { Above the range, } \mathrm{N} \\
(\%)\end{array}$ \\
\hline Uric acid ( $\mu \mathrm{mol} / \mathrm{L})$ & $\begin{array}{l}235.0 \text { (183.0 } \\
299.5)\end{array}$ & $52(33.8)$ & $4(2.6)$ & $\begin{array}{l}283.0(237.0 \\
351.0)^{*}\end{array}$ & 43 (28.6) & $0^{\#}$ \\
\hline $\begin{array}{l}\text { Urea nitrogen } \\
(\mathrm{mmol} / \mathrm{L})\end{array}$ & $3.7(3.1,4.7)$ & $35(22.7)$ & $4(2.6)$ & $3.9(3.4,4.8)$ & $17(11.5)$ & $0^{\#}$ \\
\hline Creatinine $(\mu \mathrm{mol} / \mathrm{L})$ & $65.5(52.0,77.0)$ & $3(1.9)$ & $1(0.6)$ & $59.0(48.0,71.0)$ & $5(3.4)$ & $1(0.7)$ \\
\hline Cystatin C (mg/L) & $0.8(0.7,0.9)$ & $15(9.7)$ & $6(3.9)$ & $0.76(0.69,0.87)$ & $14(9.5)$ & $2(1.4)$ \\
\hline eGFR (mL/min) & $\begin{array}{l}125.8(103.0 \\
148.6)\end{array}$ & $6(3.9)$ & $86(55.8)$ & $\begin{array}{l}134.1(118.7 \\
156.5)\end{array}$ & $2(1.4)$ & $72(48.6)$ \\
\hline \multicolumn{2}{|c|}{ Renal dysfunction, N (\%) } & $16(10.4 \%)$ & & & $5(3.33 \%)^{\dagger}$ & \\
\hline
\end{tabular}

Compared with "Median values" among COVID-19 patients on admission

Compared with "Above the range" among COVID-19 patients on admission, ${ }^{\#} P<0.05$

Compared with "On admission", ${ }^{\dagger} P<0.05$

${ }^{*} P<0.05$

(1.4\%) patients with eGFR were below the normal range (Table 4). Further analysis found that 5 (3.33\%) COVID19 patients in total still remained with renal dysfunction in 2 weeks after discharge (Table 4).

\section{Discussion}

This research primarily analyzed SARS-CoV-2-evoked renal dysfunction, its risk factors and prognosis in 2 weeks after discharge in a hospital-based retrospective cohort study. Our results indicate that male gender, older age and hypertension are three independently risk factors of renal dysfunction among COVID-19 patients. In addition, SARS-CoV-2-evoked renal dysfunction was not fully recovered in 2 weeks after discharge.

Mounting evidences have confirmed that SARS-CoV-2 injection evoked multiple organ injuries, primarily containing liver dysfunction, myocardial injury, lymphocyte reduction and even respiratory failure [8-11]. In this research, the levels of serum uric acid, urea nitrogen, creatinine, cystatin $\mathrm{C}$ and eGFR were detected and renal dysfunction was evaluated among COVID-19 patients between on admission and discharge. Our results indicated that creatinine and cystatin $\mathrm{C}$ were increased, eGFR was decreased in severe COVID-19 patients. No difference of uric acid, urea nitrogen and cystatin $\mathrm{C}$ were observed between mild and severe COVID-19 patients. Furthermore, the number of COVID-19 patients with renal dysfunction was more in severe patients than those in mild patients. Renal dysfunction was more pervasive in severe patients with COVID-19. Our data indicate that renal dysfunction is positively correlated with the severity of COVID-19 patients on admission.

Earlier studies have confirmed that older age elevated the risk of death in COVID-19 patients [12, 13]. Several comorbidities aggravated the severity of COVID-19 patients $[14,15]$. In this research, the influences of demographic characteristics on renal dysfunction were evaluated. No difference of urea nitrogen was observed in different gender patients. Uric acid and cystatin $\mathrm{C}$ were decreased, eGFR was increased in females. Additionally, we found that the levels of uric acid, urea nitrogen, creatinine and cystatin $C$ were higher and the level of eGFR was lower in the older patients. Furthermore, the influences of basic complications on renal dysfunction were analyzed. Our results indicated that the levels of urea nitrogen and cystatin $C$ were increased in COVID-19 patients with hypertension. Further analysis found that uric acid, urea nitrogen, creatinine and cystatin $\mathrm{C}$ were increased and eGFR was decreased in COVID-19 patients with diabetes. Furthermore, we also found that eGFR was decreased in COVID-19 patients with other chronic diseases. These evidences suggest that male gender, older age, diabetes and hypertension may aggravate the risk of renal dysfunction in COVID19 patients. For the sake of analyzing the risk factors of renal dysfunction among COVID-19 patients, multivariate logistic regression analysis was carried out. These data demonstrate that male gender, older age and hypertension are three independent risk factors of renal dysfunction among COVID-19 patients. In brief, male elderly subjects with hypertension elevates the risk of renal dysfunction in COVID-19 patients.

The prognosis of renal dysfunction remained obscure among COVID-19 patients. This is an important doubt which is worthy of exploring whether renal dysfunction of COVID-19 patients is reversed in 2 weeks after discharge. In the present project, 150 cases with COVID-19 were followed up and renal dysfunction were accessed. Every index of renal function and the rate of renal dysfunction were compared between on admission and in 2 weeks after discharge among COVID-19 patients. No difference of urea nitrogen, creatinine, cystatin $\mathrm{C}$ and 
eGFR were confirmed between on admission and after discharge. However, the level of uric acid was slightly increased in 2 weeks after discharge compared with on admission among COVID-19 patients. Moreover, the abnormal number of patients with creatinine, cystatin $\mathrm{C}$ and eGFR were similar between on admission and in 2 weeks after discharge. Interestingly, a few patients with serum creatinine, cystatin C and eGFR were still out of the normal range in 2 weeks after discharge. These data suggest that renal function indexes of $3.33 \%$ cases with COVID-19 were not fully recovered in 2 weeks after discharge. Hence, whether SARS-CoV-2-caused a longtime renal dysfunction is required to explore in the next therapeutic methods.

The mechanism of SARS-CoV-2-caused renal dysfunction is still unknown. More and more reports have revealed that SARS-CoV-2 plays a pathogenetic role in COVID-19 patients through binding to receptor of angiotension converting enzyme (ACE) 2 [16, 17]. At present, several researches demonstrated that ACE2 can express in renal tubular epithelium [18]. Therefore, we speculate that SARS-CoV-2 may directly damage kidney tissue through binding to the ACE2 receptor. Besides, earlier studies found that inflammatory cytokines were dramatically elevated in patients with COVID-19 [1921]. It is generally known that cytokine storm was associated with the process and the levels of IL- 6 and CRP can predict the severity and prognosis of COVID-19 patients $[22,23]$. IL-6 is a multifunctional cytokine that transmits cell signaling and regulates immune cells [24]. CRP is an acute-phase proinflammatory cytokine and a sensitive biomarker of infection and tissue damage [25]. The secreting of CRP or IL-6 always induces cytokine storm and damages multiple organs function. In this study, the correlations between inflammatory cytokines and renal dysfunction were evaluated among COVID-19 patients. The results indicated that there were positive correlations between renal dysfunction with IL-6 and CRP in COVID-19 patients. Consequently, these results reveal that cytokine storm may involve in the process of SARS-CoV-2-induced renal dysfunction.

There are several weaknesses in this study. Firstly, this was only a single center research, all patients were from Fuyang City in Anhui Province. Source of patients may cause selection bias. All patients with COVID-19 were timely found and treated in the Fuyang City, so COVID19 patients only were mild and severe cases in Fuyang City. The prevalence was very low and severity of renal dysfunction was modest. Secondly, renal dysfunction was evaluated only through the linear determination of biomarkers and not in an accepted and comparable way (AKIN, KADIG, etc), more assessment methods are needed to evaluate the renal dysfunction in the next project. Thirdly, because of minor specimen, a larger sample size is needed to perform. Fourthly, this current study was only a hospital-based retrospective cohort study, the mechanism by which SARS-CoV-2-induced renal dysfunction in COVID-19 patients was unclear. We can't exclude the effect of drug use patterns and doses on renal dysfunction in COVID-19 patients. More animal studies and in vivo experiment are needed to conduct in the future research.

\section{Conclusion}

All in all, this project primarily described SARS-CoV-2evoked renal dysfunction in the Second People's Hospital of Fuyang City of Anhui Province. These data reveal that renal dysfunction is more prevalent in severe patients with COVID-19. Moreover, male gender, older age and hypertension are significant differently risk factors for enal dysfunction. Our results demonstrate that renal dysfunction is not fully restored in 2 weeks after discharge in COVID-19 patients. Hence, whether SARSCoV-2 evokes a long-period renal dysfunction in COVID-19 patients is required to evaluated in COVID19 patients.

\section{Abbreviations}

COVID-19: Coronavirus disease 2019; SARS-CoV-2: Severe Acute Respiratory Syndrome Coronavirus-2; IL-6: Interleukin-6; CRP: C-reactive protein; ACE: Angiotension converting enzyme; eGFR: Estimated glomerular filtration rate

\section{Acknowledgements}

We greatly appreciate all doctors and nurses of respiratory and critical care medicine in the Second People's Hospital of Fuyang City for recruiting participators. Moreover, we also thank all patients and their families participated in this research.

\section{Authors' contributions}

L.F. and H.Z. designed research; H.X.X., J.F., Y.X., Z.X., L.Z. and X.Y.L. conducted research; H.X.X. analyzed data; L.F. and H.X.X. wrote the paper; L.F. and H.Z. had primary responsibility for final content. All authors read and approved the final manuscript

\section{Funding}

This study was supported by National Natural Science Foundation Incubation Program of the Second Affiliated Hospital of Anhui Medical University (grant number: 2019GQFY06 and 2020GQFY05). This fund facilitated data collection.

\section{Availability of data and materials}

The data generated during and/or analyzed during the current study are available from the corresponding author on reasonable request.

\section{Ethics approval and consent to participate}

This project was approved by the institutional ethics board of the Second People's Hospital of Fuyang City (No. 2020-5). Individual signed informed consent was gained from patients. In unconscious patients or those with mechanical ventilation, consent was obtained from the guardians of these participants.

\section{Consent for publication}

Not applicable.

Competing interests

The authors declare that they have no competing interests. 


\section{Author details}

'Second Affiliated Hospital, Anhui Medical University, Furong Road no 678, Hefei 230601, Anhui Province, China. ${ }^{2}$ Second People's Hospital of Fuyang City, Fuyang 236015, Anhui Province, China. ${ }^{3}$ Department of Toxicology, Anhui Medical University, 81 Meishan Road, Hefei 230032, Anhui Province, China.

Received: 1 December 2020 Accepted: 31 January 2021

Published online: 08 February 2021

\section{References}

1. Li Q, Guan X, Wu P, Wang XY, Zhou L, Tong YQ, et al. Early Transmission Dynamics in Wuhan, China, of Novel Coronavirus-Infected Pneumonia. N Engl J Med. 2020;382(13):1199-207.

2. WHO Coronavirus disease (COVID-19) outbreak. 2020. www.who.int/ emergencies/diseases/novel-coronavirus-2019.

3. Xu XT, Chen P, Wang JF, Feng JN, Zhou H, Li X, et al. Evolution of the novel coronavirus from the ongoing Wuhan outbreak and modeling of its spike protein for risk of human transmission. Sci China Life Sci. 2020;63(3):457-60.

4. World Health Organization. Coronavirus diseases 2019. www.who.int/ emergencies/diseases/novel-coronavirus-2019/events-as-they-happen.

5. Kumar S, Poonam, Rathi B. Coronavirus disease COVID-19: a new threat to public health. Curr Top Med Chem. 2020;20(8):599-600.

6. Abd El-Aziz TM, Stockand JD. Recent progress and challenges in drug development against COVID-19 coronavirus (SARS-CoV-2) - an update on the status. Infect Genet Evol. 2020;83:104327.

7. Wang D, Hu B, Hu C, Zhu FF, Liu X, Zhang J, et al. Clinical characteristics of 138 hospitalized patients with 2019 novel coronavirus-infected pneumonia in Wuhan, China. JAMA. 2020;323(11):1061-9.

8. Fu L, Fei J, Xiang HX, Xiang Y, Li MD, et al. Influence factors of death risk among COVID-19 patients in Wuhan, China: a hospital-based case-cohort study. MedRxiv. 2020;035329. https://doi.org/10.1101/2020.03.13.20035329.

9. Fei J, Fu L, Li Y, Xiang Y, Xiang HX, Li MD, et al. Reduction of lymphocyte at early stage elevates severity and death risk of COVID-19 patients: a hospitalbased case-cohort study. Arch Med Sci. 2020. https://doi.org/10.5114/aoms. 2020.99006.

10. Fu L, Fei J, Xu S, Xiang HX, Xiang Y, Hu B, et al. Liver dysfunction and its association with the risk of death in COVID-19 patients: a prospective cohort study. J Clin Transl Hepatol. 2020;8(3):246-54.

11. Xiao SY, Wu Y, Liu H. Evolving status of the 2019 novel coronavirus infection: proposal of conventional serologic assays for disease diagnosis and infection monitoring. J Med Virol. 2020;92(5):464-7.

12. Lai CC, Shih TP, Ko WC, Tang HJ, Hsueh PR. Severe acute respiratory syndrome coronavirus 2 (SARS-CoV-2) and coronavirus disease-2019 (COVID19): the epidemic and the challenges. Int J Antimicrob Agents. 2020;55(5): 105924.

13. Yao QC, Wang $P$, Wang XG, Qie GQ, Meng $M$, Tong XW, et al. A retrospective study of risk factors for severe acute respiratory syndrome coronavirus 2 infections in hospitalized adult patients. Pol Arch Intern Med. 2020;130(5):390-9.

14. Wang TB, Du Z, Zhu FX, Cao ZL, An YZ, Gao Y, et al. Comorbidities and multi-organ injuries in the treatment of COVID-19. Lancet. 2020;395(10228): e52.

15. Richardson S, Hirsch JS, Narasimhan M, Crawford JM, McGinn T, Davidson $\mathrm{KW}$, et al. Presenting characteristics, comorbidities, and outcomes among 5700 patients hospitalized with COVID-19 in the New York City Area. JAMA. 2020;323(20):2052-9.

16. Lan J, Ge JW, Yu JF, Shan SS, Zhou H, Fan SL, et al. Structure of the SARSCOV-2 spike receptor-binding domain bound to the ACE2 receptor. Nature. 2020;581(7807):215-20.

17. Hoffmann M, Kleine-Weber H, Schroeder S, Krüger N, Herrler T, Erichsen S, et al. SARS-CoV-2 cell entry depends on ACE2 and TMPRSS2 and is blocked by a clinically proven protease inhibitor. Cell. 2020;181(2):271-80.e8.

18. Lely A, Hamming I, van Goor H, Navis G. Renal ACE2 expression in human kidney disease. J Pathol. 2004;204(5):587-93.

19. Li N, Han L, Peng M, LV YX, Ouyang Y, Liu K, et al. Maternal and neonatal outcomes of pregnant women with COVID-19 pneumonia: a case-control study. Clin Infect Dis. 2020;71(16):2035-41.

20. Zhang C, Wu Z, Li JW, Zhao H, Wang GQ. The cytokine release syndrome (CRS) of severe COVID-19 and Interleukin-6 receptor (IL-6R) antagonist
Tocilizumab may be the key to reduce the mortality. Int J Antimicrob Agents. 2020;55(5):105954.

21. Conti P, Ronconi G, Caraffa A, Gallenga C, Ross R, Frydas I, et al. Induction of pro-inflammatory cytokines (IL-1 and IL-6) and lung inflammation by Coronavirus-19 (COVI-19 or SARS-CoV-2): anti-inflammatory strategies. J Biol Regul Homeost Agents. 2020;34(2):327-31.

22. Huang C, Wang Y, Li XW, Ren LL, Zhao JP, Hu Y, et al. Clinical features of patients infected with 2019 novel coronavirus in Wuhan, China. Lancet. 2020;39(10223):497-506.

23. Liu F, Li L, Xu MD, Wu J, Luo D, Zhu YS, et al. Prognostic value of interleukin-6, C-reactive protein, and procalcitonin in patients with COVID19. J Clin Virol. 2020;104370:127.

24. Taniguchi K, Karin M. IL-6 and related cytokines as the critical lynchpins between inflammation and cancer. Semin Immunol. 2014;26(1):54-74.

25. Mooiweer E, Luijk B, Bonten MJ, Ekkelenkamp MB. C-Reactive protein levels but not CRP dynamics predict mortality in patients with pneumococcal pneumonia. J Infect. 2011;62(4):314-6.

\section{Publisher's Note}

Springer Nature remains neutral with regard to jurisdictional claims in published maps and institutional affiliations.

\section{Ready to submit your research? Choose BMC and benefit from:}

- fast, convenient online submission

- thorough peer review by experienced researchers in your field

- rapid publication on acceptance

- support for research data, including large and complex data types

- gold Open Access which fosters wider collaboration and increased citations

- maximum visibility for your research: over $100 \mathrm{M}$ website views per year

At $\mathrm{BMC}$, research is always in progress.

Learn more biomedcentral.com/submissions 